\title{
Effect of Low Dosage Inhaled Nitric Oxide on Pulmonary Hypertension in Congenital Heart Disease
}

\author{
TAKEYO KAZUE \\ Department of Pediatrics and Child Health, Kurume University School of Medicine, \\ Kurume 830, Japan
}

Received for publication October 2, 1995

\begin{abstract}
Summary: An evaluation of the pulmonary vascular resistance and the reversibility of pulmonary vascular reaction in children with congenital heart disease is essential for determining the surgical indication and for assessing the long-term prognosis. We report the clinical efficacy of low dosage inhaled nitric oxide and investigate the relationship between its effect and hemodynamic parameters in 18 patients with congenital heart disease. The patients were divided into 3 Groups; Group 1 consisting of 3 patients with Eisenmenger syndrome, Group 2 of 10 patients whose mean pulmonary artery pressure was more than $30 \mathrm{mmHg}$, and Group 3 consisting of 5 patients whose mean pulmonary artery pressure was less than $30 \mathrm{mmHg}$. High concentration (90\%) oxygen, and also normal oxygen (21\%) containing 10 parts per million nitric oxide were administered by cardiac catheterization. In Group 1 , both the $90 \%$ oxygen and the normal oxygen with nitric oxide showed no affect on the hemodynamical variables. In Group 2, the pulmonary artery pressure and the pulmonary vascular resistance both significantly decreased with the $90 \%$ oxygen, and with the nitric oxide inhalation, but these decreases were not found in Group 3. In the 15 patients (of Groups 2 and 3 combined) who were considered to have reversible pulmonary vascular changes, significant correlations were found between the baseline pulmonary artery pressure and the magnitude of pulmonary vasodilation. No clinical evidence of toxicity was seen with the administration of the inhaled nitric oxide. These data suggested that inhaled nitric oxide, even in a low dosage, was a potent and selective pulmonary vasodilator in patients with congenital heart disease complicated with pulmonary hypertension. Since a positive correlation was found between the baseline pulmonary artery pressure and the magnitude of pulmonary vasodilation, this examination demonstrated potential efficacy for objective analysis in patients with pulmonary hypertension.
\end{abstract}

Key words: congenital heart disease - nitric oxide - pulmonary hypertension - endothelium-derived relaxing factor - pulmonary vascular resistance 


\section{Introduction}

Congenital heart disease with increased pulmonary blood flow or pulmonary venous obstruction may produce pulmonary arterial smooth muscle hypertrophy, hyperbolas and/or pulmonary vasoconstriction (Rabinovitch, 1995). If surgical correction of the underlying congenital heart lesion is not performed in the early stages, then pulmonary vasoconstriction may persist and progress to irreversible vascular obliteration with high morbidity, such as Eisenmenger syndrome (Rabinovitch, 1995). For that reason, an evaluation of the pulmonary vascular resistance and reversibility of the pulmonary vascular reaction in children with increased pulmonary vascular resistance is important to determine the surgical indication and assess the longterm prognosis.

Recent studies have revealed that one of the major components of endothelium-derived relaxing factor is nitric oxide (Furchgott and Zawadzki, 1980), produced from L-arginine (Palmer et al. 1988) by endothelial nitric oxide synthase (Janssens et al. 1992). Because the half-life of inhaled nitric oxide is approximately 3 to $6 \mathrm{sec}$ onds, it produces vasodilation only in the pulmonary arteries (Fig. 1). Thus, inhalation of nitric oxide in patients with increased pulmonary vascular resistance due to left to right shunt can be considered as an ideal supplement for investigating the reversibility of pulmonary vascular disease. Although the optimal concentration of nitric oxide for this purpose is still controversial, recent studies have suggested that the clinical effect of a low dosage of nitric oxide in the range of 6 to 12 parts per million (ppm) was

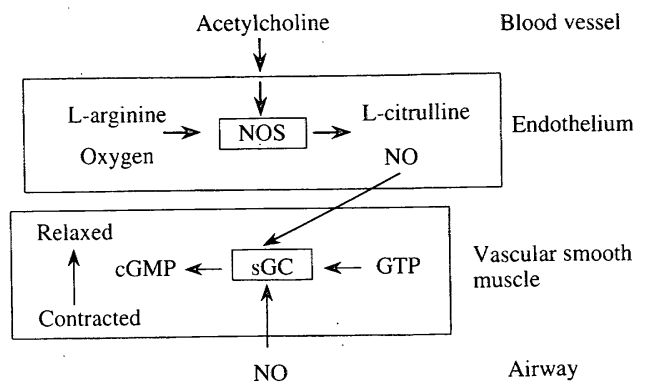

Fig. 1. Physiological and pharmacological actions of nitric oxide on vascular smooth muscle. cGMP: cyclic guanosine monophosphate; GTP: guanosine triphosphate; NO: nitric oxide; NOS: nitric oxide synthase; sGC: soluble guanylate cyclase

sufficient, compared to a much higher concentration (Kinsella et al. 1992; Day et al. 1995). If such phenomena are correct, then inhalation of a low dosage of nitric oxide may avoid the toxic production of nitrogen dioxide, and thus ensure more safety.

The purpose of this study was to evaluate the clinical efficacy of low dosage inhaled nitric oxide in patients with pulmonary hypertension and to investigate the relationship between its effect and hemodynamic parameters.

\section{Patients and Methods}

\section{Patients}

Eighteen patients were evaluated in this study (Table 1). These patients were divided into 3 groups as follows. Group 1 consisted of 3 patients with clinically and hemodynamically diagnosed Eisenmenger syndrome, whose mean age was $18.3 \pm 4.0$ years and mean body weight was $50.1 \pm$ 
TABLE 1.

Patients characteristics

\begin{tabular}{|c|c|c|c|c|c|c|}
\hline Group & Patient & Age/Sex & Lesion & Medication : & Other Condition & $\mathrm{PH}$ \\
\hline & 1 & 21 years/F & VSD & digoxin, furosemide, PGI2 & Eisenmenger synd. & + \\
\hline \multirow[t]{6}{*}{1} & 2 & 17 years/F & VSD post ope & digoxin, furosemide, PGI2 & Eisenmenger synd. & + \\
\hline & 3 & 15 years $/ \mathrm{F}$ & VSD & - & Trisomy 21, Eisenmenger synd. & + \\
\hline & 4 & 14 years/F & AVSD post ope. complete AV block & - & Trisomy 21 & + \\
\hline & 5 & 2 years/M & VSD & digoxin & - & + \\
\hline & 6 & 1 month/F & VSD, CoA & digoxin, furosemide & - & + \\
\hline & 7 & 4 months/M & VSD & digoxin, furosemide & - & + \\
\hline \multirow[t]{8}{*}{2} & 8 & 1 years/M & VSD,Mr & digoxin & Trisomy 21 & + \\
\hline & 9 & 6 months/M & VSD, ASD & digoxin & Trisomy 21 & + \\
\hline & 10 & 9 months/F & VSD, PDA, val AS & digoxin, furosemide & - & + \\
\hline & 11 & 8 months/M & $\mathrm{ASD}, \mathrm{Mr}$ & digoxin & - & + \\
\hline & 12 & 1.7 years $/ \mathrm{M}$ & ASD & digoxin, furosemide, PGI2 & Trisomy 21 & + \\
\hline & 13 & 14 years/M & val $\mathrm{AS}, \mathrm{Mr}$ & digoxin, furosemide, PGI2 & - & + \\
\hline & 14 & 5 years/M & VSD & - & - & - \\
\hline & 15 & 13 years/M & VSD & - & - & - \\
\hline \multirow[t]{3}{*}{3} & 16 & 13 years $/ F$ & ASD & - & - & - \\
\hline & 17 & 14 years/F & ASD & - & - & - \\
\hline & 18 & 9 years/M & $\mathrm{VSD}$ & - & - & - \\
\hline
\end{tabular}

ASD: atrial septal defect; AVSD: atrioventricular septal defect; CoA: coarctation of the aorta; complete AV block: complete atrioventricular block; Mr: mitral regurgitation; ope: operation; PDA: patent ductus arteriosus; PGI2: prostacyclin I2; PH: pulmonary hypertension; val AS: valvular aortic stenosis; VSD: ventricular septal defect

$5.1 \mathrm{~kg}$. Group 2 consisted of 10 patients with pulmonary hypertension whose baseline mean pulmonary artery pressure was at more than $30 \mathrm{mmHg}$, with a mean age of $3.4 \pm 5.8$ years and a mean body weight of $13.3 \pm 14.1 \mathrm{~kg}$. And Group 3 consisted of 5 patients with a normal pulmonary artery pressure having a baseline mean pulmonary artery pressure of less than $30 \mathrm{mmHg}$, with a mean age of $10.8 \pm 3.8$ years and a mean body weight of $31.9 \pm$ $13.1 \mathrm{~kg}$. The clinical trial protocol for inhaled nitric oxide according to the Guidelines of the Japan Ministry of Health and Welfare was followed (Nakamura et al. 1995). Informed consent was obtained from the patients or their parents.

\section{Methods}

After routine diagnostic cardiac catheterization, we investigated separately the hemodynamic influence of inhaled high concentration oxygen (90\%) and that of $10 \mathrm{ppm}$ nitric oxide in air (21\% oxygen). After the placement of catheters into the main pulmonary artery and the descending aorta, the blood pressure at both sites was measured simultaneously. In patients with intracardiac shunting, the pulmonary and systemic blood flows were determined by Fick's principle.

Sixteen patients were studied while breathing spontaneously through a nonrebreathing face mask, while the other 2 
patients were under mechanical ventilation. After baseline measurements using room air, the high concentration oxygen was delivered to the patient for $10 \mathrm{~min}$ and measurements were repeated. After confirming the pulmonary and systemic arterial pressures had returned to baseline levels, then $10 \mathrm{ppm}$ nitric oxide with $21 \%$ oxygen was delivered for 10 min. The fraction of inspired oxygen was maintained during studies with a combination of 10 liter/min air and oxygen. During these procedures, the pressures in the pulmonary artery and descending aorta were monitored. The concentration of nitric oxide was sampled just prox- imal to the face mask.

\section{Nitric oxide delivery system}

Medical-grade nitric oxide (1000 ppm) and $\mathrm{N}_{2}$ gas were mixed with varying quantities of air and oxygen shortly before introduction into the 1-1 reservoir of a pediatric nonrebreathing mask worn by the patient. This. system allowed separate regulation of the inspired concentrations of nitric oxide, oxygen and room air. Inspired gas was monitored continuously from a port proximal to the breathing tube. Nitric oxide and nitrogen dioxide were measured using a NOA-7000 (Shimazu, Kyoto). The nitrogen dioxide

TABLE 2.

Hemodynamic variables

\begin{tabular}{|c|c|c|c|c|c|c|c|c|c|c|c|c|}
\hline \multirow{2}{*}{ Group } & \multicolumn{3}{|c|}{ PAP (mean) } & \multicolumn{3}{|c|}{$\mathrm{AoP}$ (mean) } & \multicolumn{3}{|c|}{ PVRI } & \multicolumn{3}{|c|}{ SVRI } \\
\hline & $\mathrm{R}$ & $\mathrm{O} 2$ & NO & $\mathrm{R}$ & $\mathrm{O} 2$ & NO & $\mathrm{R}$ & $\mathrm{O} 2$ & NO & $\mathrm{R}$ & $\mathrm{O} 2$ & NO \\
\hline \multirow[t]{3}{*}{1} & 90 & 92 & 88 & 120 & 120 & 120 & 2098 & 1531 & 2213 & 1922 & 1720 & 1902 \\
\hline & 75 & 75 & 72 & 80 & 80 & 90 & 1548 & 1518 & 1849 & 1728 & 1632 & 2369 \\
\hline & 78 & 85 & 85 & 90 & 100 & 90 & 1874 & 1333 & 1400 & 1884 & 2289 & 1530 \\
\hline \multirow[t]{10}{*}{2} & 90 & 80 & 50 & 90 & 95 & 100 & 2567 & 1589 & 809 & 2916 & 2281 & 2412 \\
\hline & 37 & 25 & 25 & 75 & 85 & 85 & 520 & 160 & 184 & 1933 & 1020 & 1813 \\
\hline & 40 & 40 & 40 & 65 & 55 & 60 & 720 & 329 & 563 & 3129 & 2640 & 3146 \\
\hline & 30 & 24 & 18 & 60 & 45 & 40 & 356 & 62 & 160 & 2622 & 1528 & 1594 \\
\hline & 75 & 60 & 40 & 90 & 70 & 80 & 922 & 266 & 150 & 1943 & 1020 & 2112 \\
\hline & 55 & 50 & 50 & 65 & 65 & 65 & 835 & 411 & 411 & 2643 & 2657 & 2657 \\
\hline & 90 & 42 & 50 & 75 & 70 & 70 & 632 & 248 & 312 & 1696 & 1578 & 1429 \\
\hline & 38 & 28 & 25 & 85 & 85 & 85 & 557 & 266 & 462 & 3330 & 3600 & 4213 \\
\hline & 45 & 30 & 30 & 80 & 90 & 100 & 893 & 612 & 578 & 1925 & 2140 & 2731 \\
\hline & 58 & 60 & 45 & 65 & 65 & 65 & 1044 & 1152 & 544 & 2359 & 2196 & 1952 \\
\hline \multirow[t]{5}{*}{3} & 27 & 22 & 21 & 95 & 92 & 102 & 469 & 327 & 196 & 2480 & 3233 & 2320 \\
\hline & 14 & 12 & 14 & 87 & 84 & 96 & 152 & 121 & 136 & 1385 & 1615 & 1375 \\
\hline & 14 & 16 & 14 & 70 & 80 & 85 & 108 & 87 & 108 & 2690 & 3016 & 2619 \\
\hline & 15 & 13 & 12 & 85 & 90 & 90 & 144 & 84 & 72 & 1992 & 1252 & 2229 \\
\hline & 13 & 12 & 12 & 80 & 90 & 70 & 203 & 108 & 161 & 2072 & 1384 & 2690 \\
\hline
\end{tabular}

AoP: aortic pressure (mmHg) ; NO: nitric oxide $(10 \mathrm{ppm})$; O2: $90 \%$ oxygen ; PAP: pulmonary artery pressure (mmHg) ; R: room air ; PVRI: pulmonary vascular resistance index (dynes*sec*cm-5*M-2) ; Qp/Qs: pulmonary to systemic blood flow ratio ; Rp/Rs: pulmonary to systemic vascular resistance index ratio ; SVRI: systemic vascular resistance index (dynes*sec*cm-5*M-2) 
concentration was always less than 0.1 ppm throughout this study. The waste gas from this study was extracted to outside the room.

\section{Hemodynamic evaluations}

The mean pulmonary artery pressure (PAP), mean aortic pressure (AoP), right atrial pressure, pulmonary capillary wedge pressure and arterial oxygen saturation $\left(\mathrm{SaO}_{2}\right)$ were measured during the examination. Using the measured variables, the systemic vascular resistance index (SVRI) and pulmonary vascular resistance index (PVRI) were calculated. To compare the response of the pulmonary vascular resistance to the inhaled nitric oxide between groups 2 and 3, the following variables were analyzed.

$\% \mathrm{PAP}=($ baseline $\mathrm{PAP} \cdot \mathrm{PAP}$ with nitric oxide/baseline PAP)

\%PVRI=(baseline PVRI - PVRI with nitric oxide/baseline PVRI)

$\% \mathrm{Rp} / \mathrm{Rs}=$ (baseline $\mathrm{Rp} / \mathrm{Rs} \cdot \mathrm{Rp} / \mathrm{Rs}$ with nitric oxide/baseline $\mathrm{Rp} / \mathrm{Rs}$ )

\section{Statistical analysis}

Data were expressed as mean \pm standard deviation. Student's paired t test

\begin{tabular}{ccl|ccc|cc|cc|rr}
\hline \multicolumn{3}{c|}{$\mathrm{Rp} / \mathrm{Rs}$} & \multicolumn{3}{c|}{$\mathrm{Qp} / \mathrm{Qs}$} & \multicolumn{2}{c|}{ \%PAP } & \multicolumn{2}{|c|}{ \%PVRI } & \multicolumn{2}{|c}{ \%SVRI } \\
\hline $\mathrm{R}$ & $\mathrm{O} 2$ & $\mathrm{NO}$ & $\mathrm{R}$ & $\mathrm{O} 2$ & $\mathrm{NO}$ & $\mathrm{O} 2$ & $\mathrm{NO}$ & $\mathrm{O} 2$ & $\mathrm{NO}$ & $\mathrm{O} 2$ & $\mathrm{NO}$ \\
\hline 1.09 & 0.89 & 1.16 & 0.79 & 1.05 & 1.33 & -0.022 & 0.022 & 0.270 & -0.055 & 0.105 & 0.01 \\
0.9 & 0.93 & 0.78 & 1.00 & 1.00 & 1.00 & 0.00 & 0.04 & 0.019 & -0.194 & 0.056 & -0.371 \\
0.99 & 0.58 & 0.91 & 0.85 & 1.40 & 1.00 & -0.09 & -0.09 & 0.289 & 0.253 & -0.215 & 0.188 \\
\hline 0.88 & 0.70 & 0.34 & 1.03 & 1.07 & 1.13 & 0.111 & 0.444 & 0.381 & 0.685 & 0.218 & 0.173 \\
0.27 & 0.16 & 0.10 & 1.49 & 1.35 & 2.09 & 0.324 & 0.324 & 0.692 & 0.646 & 0.472 & 0.062 \\
0.23 & 0.12 & 0.18 & 1.83 & 5.50 & 3.00 & 0.00 & 0.000 & 0.543 & 0.218 & 0.156 & -0.005 \\
0.14 & 0.04 & 0.10 & 2.50 & 8.00 & 2.04 & 0.20 & 0.400 & 0.826 & 0.551 & 0.417 & 0.392 \\
0.47 & 0.26 & 0.07 & 2.07 & 2.85 & 5.08 & 0.20 & 0.467 & 0.711 & 0.837 & 0.475 & -0.087 \\
0.32 & 0.15 & 0.15 & 2.44 & 4.43 & 4.43 & 0.091 & 0.091 & 0.508 & 0.508 & -0.005 & -0.005 \\
0.37 & 0.16 & 0.22 & 2.96 & 2.96 & 2.69 & 0.533 & 0.444 & 0.608 & 0.506 & 0.07 & 0.157 \\
0.17 & 0.073 & 0.11 & 2.45 & 3.83 & 2.31 & 0.263 & 0.342 & 0.522 & 0.171 & -0.081 & -0.265 \\
0.46 & 0.29 & 0.21 & 1.16 & 1.06 & 1.28 & 0.333 & 0.333 & 0.315 & 0.353 & -0.112 & -0.419 \\
0.44 & 0.52 & 0.28 & 1.00 & 1.00 & 1.00 & -0.034 & 0.224 & -0.103 & 0.479 & 0.069 & 0.173 \\
\hline 0.19 & 0.10 & 0.085 & 1.29 & 1.63 & 2.31 & 0.185 & 0.222 & 0.303 & 0.582 & -0.304 & 0.065 \\
0.11 & 0.08 & 0.10 & 1.00 & 1.18 & 1.00 & 0.143 & 0.000 & 0.204 & 0.105 & -0.166 & -0.007 \\
0.04 & 0.029 & 0.041 & 4.24 & 5.80 & 3.23 & -0.143 & 0.000 & 0.194 & 0.000 & -0.121 & 0.026 \\
0.07 & 0.07 & 0.00 & 1.50 & 1.19 & 2.10 & 0.133 & 0.200 & 0.417 & 0.500 & 0.371 & -0.119 \\
0.10 & 0.08 & 0.06 & 1.55 & 1.59 & 2.06 & 0.077 & 0.077 & 0.468 & 0.207 & 0.332 & -0.298 \\
\hline
\end{tabular}

\%PAP: (baseline PAP-PAP with nitric oxide/baseline PAP) ; \%PVRI: (baseline PVRI-PVRI with nitric oxide/baseline PVRI) ; \%Rp/RS: (baseline Rp/Rs-Rp/Rs with nitric oxide/baseline $\mathrm{Rp} / \mathrm{Rs}$ ) 
was used to compare the variables in the same group. For comparing the percent variables between Groups 2 and 3, the unpaired t test was used. Standard linear regression analysis was performed to identify correlations between variables. A $p$ value less than 0.05 was considered statistically significant.

\section{Results}

The hemodynamic variables under baseline conditions (room air), inhalation of high concentration oxygen, and inhalation of $10 \mathrm{ppm}$ nitric oxide are shown in Table 2. In Group 1, both high concentration oxygen and $10 \mathrm{ppm}$ nitric oxide
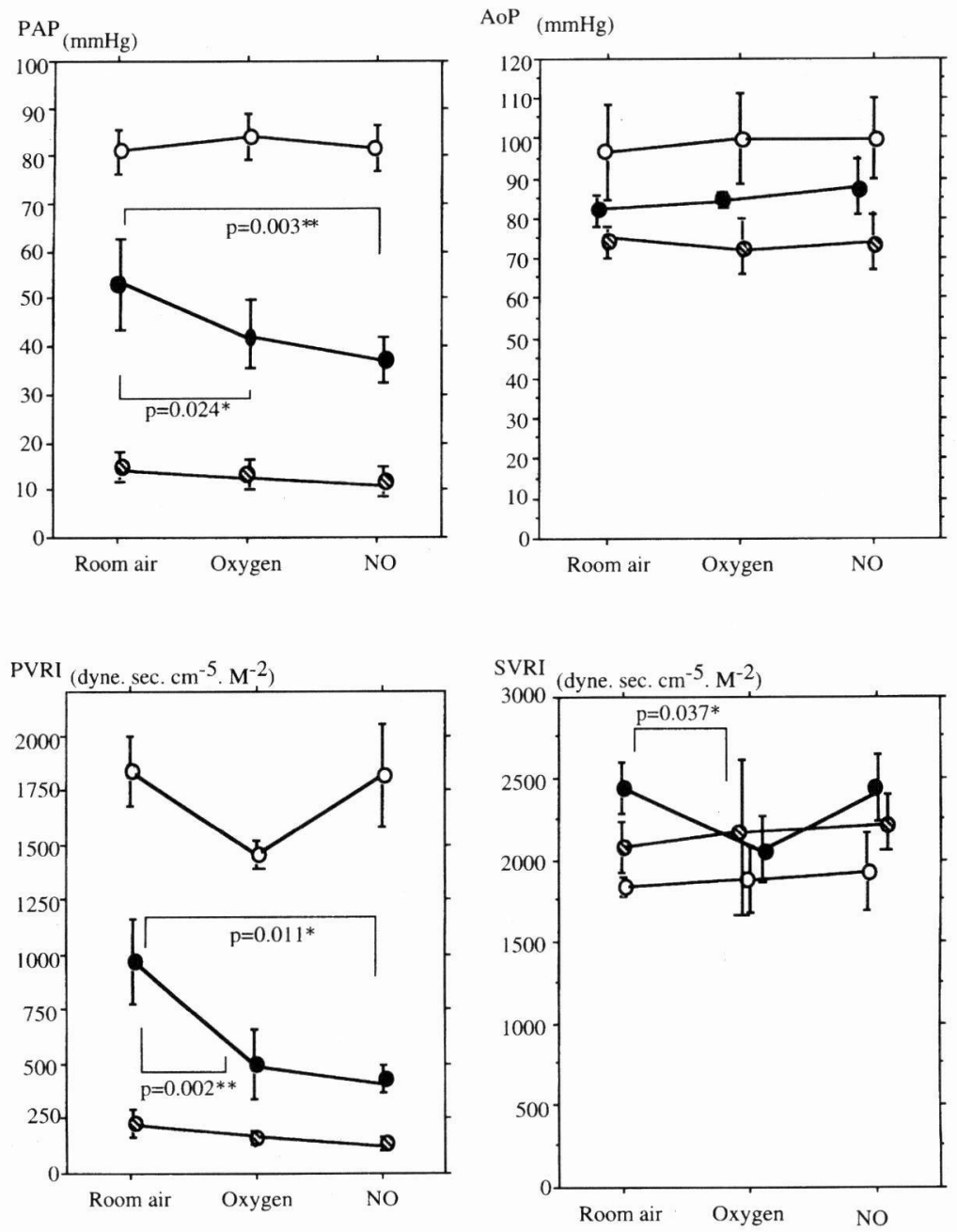

Fig. 2. Influences of inhaled high concentration oxygen and nitric oxide on PAP, AoP, PVRI and SVRI of group $1(\bigcirc), 2(\Theta), 3(\theta)$. Date are expressed as mean and standard error. Oxygen; 90\% high concentration oxygen, NO; $10 \mathrm{ppm}$ nitric oxide inhalation. 

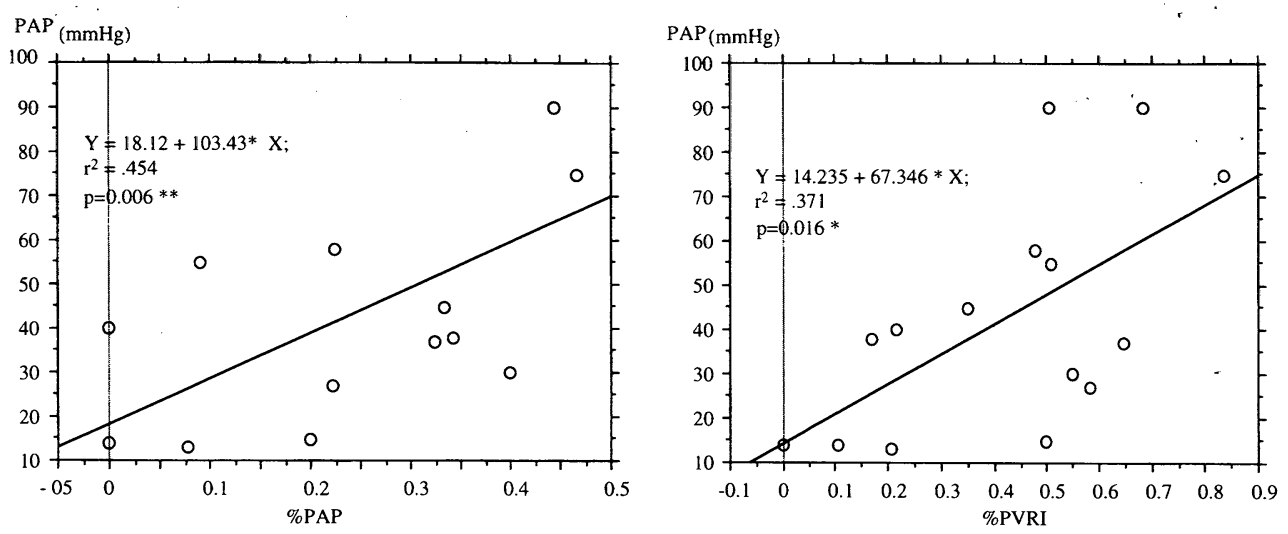

Fig. 3. Correlation between baseline pulmonary artery pressure and percent variables in patients with group 2 and 3. Date are expressed as mean and standard deviation.

did not affect the PAP, AoP, PVRI or SVRI (Fig. 2). In Group 2, both the high concentration oxygen and the nitric oxide significantly decreased the PAP and the PVRI, but did not affect the AoP. In Group 2, the nitric oxide did not affect the SVRI, but the high concentration oxygen significantly decreased it. In Group 3, both oxygen and nitric oxide inhalation did not affect the PAP, AoP, PVRI or SVRI. Over all 15 patients in Groups 2 and 3 combined, significant correlations were found between the baseline PAP and \%PAP, and between the baseline PAP and \%PVRI (Fig. 3). In patients with an elevated baseline PAP, the response of the pulmonary vascular bed for inhaled nitric oxide was higher than in those with no elevated PAP. No clinical evidence of toxicity was recognized with any administration of inhaled nitric oxide. Methehemoglobin levels remained below $1.5 \%$ in all patients during nitric oxide administration.

\section{Discussion}

Congenital heart disease with increased pulmonary blood flow can cause pulmonary artery hypertension with vascular smooth muscle hyperplasia and/or hypertrophy (Hoffman et al. 1981). After corrective cardiac surgery, some of these morphological changes might not regress sufficiently to accommodate postoperative hemodynamic changes. It is therefore desirable to predetermine the vasodilator capacity of the pulmonary circulation during preoperative cardiac catheterization to predict the postoperative pulmonary vascular resistance. Inhalation of high concentration oxygen has been used to determine the vasodilator response of pulmonary circulation (Finer et al. 1994). Although this inhalation test is convenient and widely used to assess pulmonary vascular reversibility, the objective evaluation of the pulmonary vascular resistance combined with Fick's principle is often difficult because of the interaction with the free oxygen present 
in the plasma. Although SVRI is not influenced by high concentration oxygen theoretically, decreasing SVRI was statistically observed in patients with pulmonary hypertension (Group 2) in our study. If free oxygen is present in circulating blood, the venous oxygen concentration may be at a higher than theoretical level, leading to overestimation of the systemic blood flow or effective pulmonary blood flow. Such findings have been previously reported (Miller et al. 1994).

Currently, several vasodilator agents, including prostacyclin (Bush et al. 1986), tolazoline (Gouyon and Françoise, 1992), prostaglandin $\mathrm{E}_{1}$ and sodium nitroprusside (Rubis et al. 1981) have been used for similar purposes. However, an objective evaluation of the pulmonary vascular response is complicated, because these intravenous agents are nonselective and dilate both the pulmonary and systemic vascular bed simultaneously.

Inhalation of nitric oxide does not produce systemic vasodilation because nitric oxide is rapidly bound to hemoglobin (with 1500 times the affinity of carbon monoxide). Therefore, when administered via the airways, it is taken up by hemoglobin before it reaches to the systemic vasculature. The potential utility of inhaled nitric oxide in the treatment of pulmonary hypertension was first suggested by Pepke-Zaba et al. in 1991. After several primitive studies, this treatment has become widely recognized as a treatment of first-choice for various conditions with pulmonary hypertension, such as persistent pulmonary hypertension in the newborn (Kinsella and Abman, 1995), adult respiratory distress syndrome (Abman et al. 1994), pulmonary hyperten- sive crisis after cardiac surgery (Journois et al. 1994), and after lung transplantation (Adatia et al. 1994). Almost all studies, which investigated the clinical effects of inhaled nitric oxide, have demonstrated the rapid and selective reduction of the pulmonary arterial pressure with no serious complication.

We have now extended these observations by using low-dosage inhaled nitric oxide in 18 patients with congenital heart disease. Both oxygen and nitric oxide inhalation did not affect the pulmonary circulation in patients with Eisenmenger syndrome. However, significant reductions in the pulmonary artery pressure and in the pulmonary vascular resistance were found in patients with pulmonary hypertension, but not in those without pulmonary hypertension. The major findings are that the magnitude of the response to inhaled nitric oxide was associated with the initial pulmonary artery pressure; the higher pulmonary artery pressure the greater the response, in all patients except those with Eisenmenger syndrome.

The mechanisms for different responses to inhaled nitric oxide between those with and those without pulmonary hypertension is unclear. We suggest that the mechanism may involve the pathology of pulmonary vascular bed. Recently, such pathological findings were confirmed visually using intravascular ultrasound imaging (Ishii et al. 1995).

The efficacy of inhaled $10 \mathrm{ppm}$ nitric oxide in room air in this study was important, because the combination of high dosage oxygen and high dosage nitric oxide can lead to the toxic production of nitrogen dioxide, and current guidelines advise not using nitrogen dioxide above 5 ppm (Foubert et al. 1992). Some inves- 
tigators have recently suggested that even lower levels of nitrogen dioxide (1 to $2 \mathrm{ppm}$ ) may affect pulmonary immune cells (Frampton et al. 1992; Sandström et al. 1992).

There are some limitations in this study. The mean age at study among the 3 groups did not match. It is well known that pulmonary vascular resistance in the newborn or infant is higher than in adults. However, the pulmonary vascular resistance in this study was related not only to age but also to the amount of left to right shunt. In our study of a small number of patients, we observed pulmonary vasodilation at a very low dosage $(10 \mathrm{ppm})$ of nitric oxide. ,However, the protocol of our study did not permit us to investigate any potential dosage-response relationship. Previous studies reported that selective pulmonary vasodilation occurred clinically using 20 to $80 \mathrm{ppm}$, Kinsella et al. in 1992, reported a good response from nitric oxide at $6 \mathrm{ppm}$ in neonates with persistent pulmonary hypertension but have not commented on patients with congenital heart disease. Firm conclusions therefore regarding a dosage-response at low dosages will require further studies.

In conclusion, the present study demonstrated that a low dosage of inhaled nitric oxide could selectively reduce the pulmonary vascular resistance without affecting systemic circulation and with no critical side effects with brief exposure, when the pulmonary vascular bed was reversible. Since a positive correlation was found between the baseline pulmonary artery pressure and the magnitude of pulmonary vasodilation, this examination demonstrated the potential efficacy for objective analysis in patients with increased pulmonary vascular resistance.

Acknowledgments: The author thanks Professor Hirohisa Kato, (Chairman, Dept. of Pediatrics and Child Health, Kurume University School of Medicine) for his advice and suggestions. The author also thanks Drs. Teiji Akagi, Kanoko Hashino, Tetsu Sugimura and Yasuki Maeno, for their kind technical assistance.

\section{References}

Abman, S.H., Griebel, J.L., Parker, D.K., Schmidt, J.M., Swanton, D. et al. (1994). Acute effects of inhaled nitric oxide in children with severe hypoxemic respiratory failure. J. Pediatr. 124, 881-888.

Adatia, I., Lillehei, C., Arnold, J.H., Thompson, J.E., PALAZzo, R. et al. (1994). Inhaled nitric oxide in the treatment of postoperative graft dysfunction after lung transplantation. Ann. Thorac. Surg. 57, 1311-1318.

Bush, A., Busst, C., Bоотн, K., KNight, W.B. and Shinbourne, E.A. (1986). Does prostacyclin enhance the selective pulmonary vasodilator effect of oxygen in children with congenital heart disease? Circulation 74, 135-144.

DAY, R.W., LyNCH, J.M., SHADDY, R.E. and ORSMOND, G.S. (1995). Pulmonary vasodilatory effects of 12 and 60 parts per million inhaled nitric oxide in children with ventricular septal defect. Am. J. Cardiol. 75, 196-198.

Finer, N.N., Etches, P.C., Kamstra, B., Tierney, A.J., PELIowsk, A. et al. (1994). Inhaled nitric oxide in infants referred for extracorporeal membrane oxygenation: dose response. J. Pediatr. 124, 302-308.

Foubert, L., Fleming, B., Latimer, R., Jonas, M., Oduro, A. et al. (1992). Safety guidelines for use of nitric oxide (Letter). Lancet 339, 16151616.

Frampton, M.W., Voter, K.Z., Morrow, P.E., RoberTS, N.J.Jr. and GAVRAS, J.B. (1992). Effects of nitric dioxide exposure on human host defense (Abstract). Am. Rev. Respir. Dis. 
145, A455.

Furchgott, R.F. and ZaWAdzkI, J.V. (1980). The obligatory role of endothelial cells in the relaxation of arterial smooth muscle by acetylcholine. Nature 288, 373-376.

Gouyon, J.B. and Françoise, M. (1992). Vasodilators in persistent pulmonary hypertension of the newborn: a need for optimal appraisal of efficacy. Dev.. Pharmacol. Ther. 19, 62-68.

Hoffman, J.I.E., Pudolf, A.M. and Heymann, M.A. (1981). Pulmonary vascular disease with congenital heart lesions. Circulation 64, 873877.

Ishi, M., Kato, H., Kawano, T., Akagi, T., Maeno, Y. et al. (1995). Evaluation of pulmonary artery histopathologic findings in congenital heart disease: an in vitro study using intravascular ultrasound imaging. J. Am. Coll. Cardiol. 26, 272-276.

Janssens, S.P., Shimouchi, A., Quertermous, T., Bloch, D.B. and BLoch, K.D. (1992). Cloning and expression of a cDNA encoding human endothelium-derived relaxing factor/nitric oxide synthase. J. Biol. Chem. 267, 1451914522.

Journois, D., Pouard, P., Mauriat, P., Malhere, T., Voune, P. et al. (1994). Inhaled nitric oxide as a therapy for pulmonary hypertension after operations for congenital heart defects. J. Thorac. Cardiovasc. Surg. 107, 1129-1135.

Kinsella, J.P. and Abman, S.H. (1995). Recent developments in the pathophysiology and treatment of persistent pulmonary hypertension of the newborn. J. Pediatr. 126, 853-864.

Kinsella, J.P., Neish, S.R., Shaffer, E. and Abman, S.H. (1992). Effect of low dose inhalational nitric oxide in pulmonary hypertension of the newborn. Lancet 340, 819-820.;

Miller, O.I., Celermajer, D.S., Deanfield, J.E. and MACRAE, D.J. (1994). Very-low-dose inhaled nitric oxide: A selective pulmonary vasodilator after operations for congenital heart disease. J. Thorac. Cardiovasc. Surg. 108, 487-494.

Nakamura, T., Takada, M. and Miyasaka, K. (1995). Nitric oxide and pulmonary hypertension. Pediatrics 36, 997-1006. (in Japanese)

Palmer, R.M.J., Ashton, D.S. and Moncada, S. (1988). Vascular endothelial cells synthesize nitric oxide from L-arginine. Nature 333, 664-666.

Pepke-Zaba, J., Higenbottam, T.W., Dinh-Xuan, A.T., Stone, D. and Wallwork, J. (1991). Inhaled nitric oxide as a cause of selective pulmonary vasodilation in pulmonary hypertension. Lancet 338, 1173-1174.

Rabinovitch, M. (1995). Pathophysiology of pulmonary hypertension. In Heart Disease in Infants, Children, and Adolescents, ed. Emmanouilides, G.C., Riemenschneider, T.A., Allen, H.D. and Gutgesell, H.P., pp. 1659-1695. Baltimore: Williams \& Wilkins.

Rubis, L.J., Stephenson, L.W., Johnston, M.R., NAGARAJ, S. and EDmunds, L.H.J. (1981). Comparison of effects of prostaglandin $\mathrm{E}_{1}$ and nitroprusside on pulmonary vascular resistance in children after open-heart surgery. Ann. Thorac. Surg. 32, 563-570.

Sandström, T., Wilnerzon-Thörn-Thorn, R., BJermer, L. and StJernberg, N. (1992). Repeated exposure to nitrogen dioxide causes a difficult cell response in the lung in comparison with single exposure (Abstract). Am. Rev. Respir. Dis. 145, A455. 